\title{
Technology Development of Unmanned Underwater Vehicles (UUVs)
}

\author{
Jinyeong Heo1, Junghoon Kim², Yongjin Kwon ${ }^{1 *}$ \\ ${ }^{1}$ Department of Industrial Engineering, Ajou University, Suwon, South Korea \\ ${ }^{2}$ The $6{ }^{\text {th }}$ R\&D Institute, Agency for Defense Development, Jinhae, South Korea \\ Email: *yk73@ajou.ac.kr
}

How to cite this paper: Heo, J., Kim, J. and Kwon, Y.J. (2017) Technology Development of Unmanned Underwater Vehicles (UUVs). Journal of Computer and Communications, 5, 28-35. https://doi.org/10.4236/jcc.2017.57003

Received: April 17, 2017

Accepted: May 13, 2017

Published: May 16, 2017

Copyright $\odot 2017$ by authors and Scientific Research Publishing Inc. This work is licensed under the Creative Commons Attribution International License (CC BY 4.0).

http://creativecommons.org/licenses/by/4.0/

\section{c) (i) Open Access}

\begin{abstract}
In recent years, the weapon systems have been changing drastically because of the advancement of science technology and the change of military concept of combat. There is an unmanned system at the center of all those changes. Especially, in case of maritime environment, as the center stage of combat has changed from ocean to coastal areas, it is difficult for the existing naval forces to effectively operate in shallow waters. Therefore, unmanned underwater vehicles (UUVs) are being required at an increasing pace. In this paper, we analyze the characteristics of already developed UUVs, which are the key unmanned system of the marine battlefield environment in the future. Through the analysis of development cases and the investigation of the essential technologies, the critical design issues of UUVs are elaborated. We also suggest the future directions of the UUV technologies based on the case analysis.
\end{abstract}

\section{Keywords}

Maritime Military System, Unmanned System, UUV (Unmanned

Underwater Vehicle), UUV Operation Function, Autonomous Control

\section{Introduction}

Recently, as the development of advanced science technology and military unmanned system is continuing at an increasing pace, the pattern of warfare in the future is also changing. The warfare situation in the marine environment is expected to show a different pattern from the existing naval warfare due to introduction of unmanned underwater vehicles [1] [2]. A lot of advanced countries are spurring on the development and commercialization of UUVs [3]. UUVs are typically submarines that are capable of autonomous or remote operations. UUVs can carry out underwater missions that have been very dangerous to humans onboard or that require a very long mission time. The purpose of UUVs is 
generally classified into intelligence, surveillance and reconnaissance (ISR), mine countermeasure (MCM), and anti-submarine warfare (ASW). The main reason for the development of this UUV is that there are many military benefits to be gained from asymmetric forces like submarines. There is little chance of being detected by enemies and there are fewer acoustic and magnetic signals because all missions are carried out in underwater. The vessels can be made at a significantly lower cost than the manned submarines, and because it's unmanned, the size of the vessels can be made significantly smaller as well. Additionally, UUVs can be sent to the hostile and dangerous missions without fear of losing human lives. It can also relieve human operators from monotonous and dull missions [4]. However, as it performs missions in underwater, it must operate in a harsh environment under the high ocean current and heavy hydraulic pressure. Despite, the US and other advanced countries of military forces are increasingly developing and operating UUVs capable of the precise underwater navigation [5]. Due to many merits that those UUVs provide, the use of such systems is expected to rise rapidly in the near future [6] [7] [8] [9] [10]. The technology associated with the development of UUVs is also increasingly getting sophisticated. In this regard, the analysis of the UUV development needs to be conducted, which suggests the technological advancement of the systems. However, such analysis has not been properly conducted, according to our initial study [11] [12] [13] [14] [15]. The novelty of this paper lies in the fact that the major UUV development has been investigated, and then provides the insights towards the trends of the technological development and the most important aspects of the core technological advancement.

\section{Case Study}

Currently, the United States is most actively developing and operating the marine unmanned systems. Recently, the development trends of advanced countries have greatly emphasized the concept of autonomous operations for ISR, MCM, and ASW. Below is the status of UUV development by major countries [6]-[15].

\subsection{United States of America}

Echo Voyager

- Echo Voyager is an unmanned underwater vehicle capable of carrying out reconnaissance, deep sea exploration, and military missions. It was developed by Boeing, and capable of carrying about 20 tons of sensors or other equipment without special support vessels (see Table 1 ).

- Remus 600

- The Remus 600 is currently used by the British Navy, the US Navy, and the Japanese Maritime Self Defense Force. It is usually equipped with a side scan sonar. In addition, it can optionally be equipped with other sensors and related lighting and video cameras such as profiling sonar, sub-bottom profiler, electronic steel cameras, etc. 
Table 1. Echo voyager and Remus 600.

\begin{tabular}{|c|c|c|c|c|c|}
\hline Model & Echo Vo & & \multicolumn{3}{|c|}{ Remus 600} \\
\hline \multirow[t]{3}{*}{ Figure } & & & monerou & Renus & $=$ \\
\hline & Length & $16 \mathrm{~m}$ & Length & 3.25 & \\
\hline & Weight & 50 tons & Weight & 240 & \\
\hline \multirow[t]{3}{*}{ Spec } & Velocity & - & Velocity & 4.5 & \\
\hline & Depth & $3300 \mathrm{~m}$ & Depth & 600 & \\
\hline & Operation Time & 6 month & Operation Time & 24 & \\
\hline Main Mission & ISR & & & & \\
\hline Manufacturer & Boeing Phant & Works & Kongsbe & & \\
\hline
\end{tabular}

- LMRS (Long-Term Mine Reconnaissance)

- LMRS has verified the launching and recovery capability using the submarine's torpedo tube, and performed the mine reconnaissance through the sonar. It is a stand-alone system, and contains navigation, control, communication, data processing and obstacle avoidance capabilities (see Table 2).

- MRUUVS (Mission Reconfigurable UUV System)

- MRUUVS is launched from the submarine and performs MCM missions using synthetic aperture sonar in the area where the manned systems can't reach. And it assists the manned system by supplementing sensor range expansion. Additionally, it is a stealthy submarine (see Table 2).

\subsection{Other Nations}

- Talisman (UK)

- Talisman M can be deployed at a safe distance from the area of interest and can be loaded with Archerfish robots and Talisman L for expendable mine detection and sweeping.

- Talisman L is designed to be docked to the Talisman M. It uses a multi-camera and sonar to detect hidden explosives on shallow shores like harbors (see Table 3 ).

- HUGIN (Norway)

- This UUV is a HUGIN series developed by the Kongsberg Company in Norway. It was originally developed for military operations, such as minesweeping, ISR, and ASW, but now it is widely used for other commercial purposes. The HUGIN series has three derived types, including HUGIN 1000, HUGIN 3000 and HUGIN 4500 in terms of operating depth. It performs seabed exploration, military mine detection, naval research, and coastal research for gas and oil companies (see Table 4).

- ATLAS SeaFox MK II (Germany) 
Table 2. LMRS and MRUUVS.

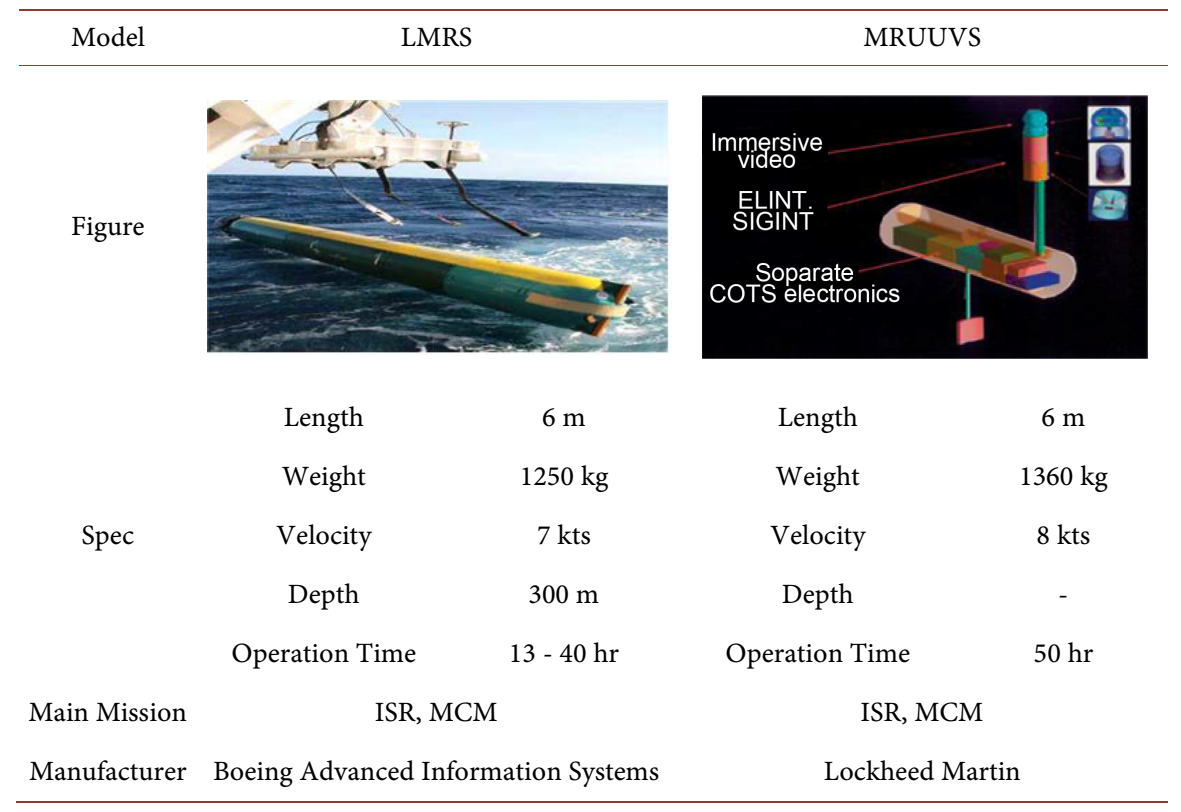

Table 3. Talisman M, L.

\begin{tabular}{|c|c|c|c|c|}
\hline Model & \multicolumn{2}{|c|}{ Talisman M } & \multicolumn{2}{|c|}{ Talisman L } \\
\hline \multirow[t]{3}{*}{ Figure } & & & & \\
\hline & Length & $6 \mathrm{~m}$ & Length & $6 \mathrm{~m}$ \\
\hline & Weight & $1250 \mathrm{~kg}$ & Weight & $1360 \mathrm{~kg}$ \\
\hline \multirow[t]{3}{*}{ Spec } & Velocity & $7 \mathrm{kts}$ & Velocity & $8 \mathrm{kts}$ \\
\hline & Depth & $300 \mathrm{~m}$ & Depth & - \\
\hline & Operation Time & $13-40 \mathrm{hr}$ & Operation Time & $50 \mathrm{hr}$ \\
\hline Main Mission & \multicolumn{2}{|c|}{ ISR, MCM } & \multicolumn{2}{|c|}{ ISR, MCM } \\
\hline Manufacturer & \multicolumn{2}{|c|}{ BAE Systems } & \multicolumn{2}{|c|}{ BAE Systems } \\
\hline
\end{tabular}

- ATLAS SeaFox MK II is a minesweeping system based on the latest technology using the extended mine disposal vehicle principles. It is able to eliminate most mines and has the advantage of high mission success rate by implementing quick and accurate operation (see Table 4).

- DOLPHIN MK I

- ISE developed the world's first semi-submersible robot for mine detection and transferred the technology to USA and France. This type of USV is being developed in many countries and is less influenced by the wave. It is recognized for its stable platform and low cost (see Table 5).

- Double Eagle SAROV 
Table 4. HUGIN 3000 and ATLAS SeaFox MK II.

\begin{tabular}{|c|c|c|c|c|}
\hline Model & HUGI & & ATLAS Se & II \\
\hline Figure & & & & \\
\hline & Length & $5.5 \mathrm{~m}$ & Length & $1.3 \mathrm{~m}$ \\
\hline & Weight & $1400 \mathrm{~kg}$ & Weight & $40 \mathrm{~kg}$ \\
\hline Spec & Velocity & $2-4 \mathrm{kts}$ & Velocity & $5 \mathrm{kts}$ \\
\hline & Depth & $3000 \mathrm{~m}$ & Depth & $300 \mathrm{~m}$ \\
\hline & Operation Time & $60 \mathrm{hr}$ & Operation Time & - \\
\hline Main Mission & & & & \\
\hline Manufacturer & Kongsber & ime & ATLAS & \\
\hline
\end{tabular}

Table 5. DOLPHIN MK and Double Eagle SAROV.

\begin{tabular}{|c|c|c|c|c|}
\hline Model & \multicolumn{2}{|c|}{ DOLPHIN MK I } & \multicolumn{2}{|c|}{ Double Eagle SAROV } \\
\hline \multirow[t]{3}{*}{ Figure } & & & & \\
\hline & Length & $5.5 \mathrm{~m}$ & Length & $1.3 \mathrm{~m}$ \\
\hline & Weight & $1400 \mathrm{~kg}$ & Weight & $40 \mathrm{~kg}$ \\
\hline \multirow[t]{3}{*}{ Spec } & Velocity & $2-4 \mathrm{kts}$ & Velocity & $5 \mathrm{kts}$ \\
\hline & Depth & $3000 \mathrm{~m}$ & Depth & $300 \mathrm{~m}$ \\
\hline & Operation Time & $60 \mathrm{hr}$ & Operation Time & - \\
\hline Main Mission & \multicolumn{2}{|c|}{$\mathrm{MCM}$} & \multicolumn{2}{|c|}{ ISR, MCM } \\
\hline Manufacturer & \multicolumn{2}{|c|}{$\begin{array}{c}\text { International } \\
\text { Submarine Engineering }\end{array}$} & \multicolumn{2}{|c|}{ SAAB } \\
\hline
\end{tabular}

- Double Eagle SAROV is a hybrid UUV that can be operated in two ROV/ AUV modes. Its main missions include underwater search mission, mine reconnaissance, and sweeping. Also, it is cost-effective and equipped with fast mine detection and sweeping system (see Table 5).

\section{Analysis}

In this section, we derive the required functions and the technologies of UUVs from the UUV development in major countries. The UUV design should be evaluated according to each mission through a detailed comparative analysis. In addition, to improve operability, it is important to have the advanced onboard equipment and to standardize the interface technology and modularization 
among the equipment. The UUVs can be categorized by the hull size, types of energy source and operation range. Those determine the endurance of the UUVs, which can be very important for the reconnaissance mission. The onboard sensors and mission equipment determine the type of missions that the UUVs can carry out. Since the UUVs are operating in deep waters where the constant connection between the remote ground operators can be highly difficult, the precise navigation capability becomes the critical issue. The autonomy level also determines the UUVs flexibility in terms of when the situations change too rapidly for the remotely situated human operators can handle. In this regards, the important information is shown in Table 6. In order for the information to be applied to the UUV design, the detailed requirements should be derived based on this result, which represent the most critical required functions. Those include the efficient energy source, a high level of autonomy, effective launch and recovery system, communications system, and the mission equipment onboard. All of these critical functions need to be developed, in order for the UUVs effectively operate as intended.

\section{Conclusion}

In this paper, through the investigation of many UUVs that are currently under development, we have identified the most important aspects of UUVs. Those include the efficient energy source, a high level of autonomy, effective launch and recovery system, communications system, and the mission equipment onboard. All of these critical functions need to be developed, in order for the UUVs to effectively operate as intended. In this regard, the main contribution of this paper is the fact that the most important required functions have been identified, if any UUVs need to be successful. Unmanned underwater vehicles represent a military equipment that can be used to covertly detect and engage in enemy harbor areas or under the enemy waters. Also, considering the development trend worldwide, it is expected that UUV systems of the higher performance levels shall be developed in the near future. The UUVs will fundamentally alter the

Table 6. Requested functions for the UUVs.

\begin{tabular}{|c|c|}
\hline \multicolumn{2}{|r|}{ Requested Function } \\
\hline $\begin{array}{l}\text { Energy source of } \\
\text { high density }\end{array}$ & $\begin{array}{l}\text { - It should provide enough power for sensors and } \\
\text { communications to perform a wide range of mission } \\
\text { from a distance }\end{array}$ \\
\hline $\begin{array}{l}\text { Autonomous mission } \\
\text { management and precision } \\
\text { navigation technology }\end{array}$ & $\begin{array}{l}\text { - It should be able to perform the missions such as } \\
\text { detecting, avoiding, engaging in threats autonomously } \\
\text { without human intervention at a distance }\end{array}$ \\
\hline $\begin{array}{l}\text { - Launching and recovery } \\
\text { technology }\end{array}$ & $\begin{array}{l}\text { - It should be easy for UUV to launch or recover } \\
\text { in the submarine }\end{array}$ \\
\hline $\begin{array}{l}\text { - Communication and } \\
\text { network technology }\end{array}$ & $\begin{array}{l}\text { - It should be as little as possible from the effects of } \\
\text { scattering and attenuation in underwater }\end{array}$ \\
\hline $\begin{array}{l}\text { - Sensor and mission } \\
\text { equipment technology }\end{array}$ & $\begin{array}{l}\text { - It should be equipped with appropriate sensors } \\
\text { according to mission }\end{array}$ \\
\hline
\end{tabular}


way the war is being fought. Regardless of the shallow waters or deep sea waters of the enemy territory, the UUVs will be increasingly deployed to conduct highly dangerous missions that have never been possible by legacy naval system. The major countries around the world already see the potential of UUVs in the maritime warfare and continue to develop them into a higher level. Such trend will continue in the foreseeable future.

\section{Acknowledgements}

This work was supported by the Agency for Defense Development (ADD) under the Contract No. UD160008DD. The authors wish to express sincere gratitude for the financial support.

\section{References}

[1] Choe, J., Kim, C. and Kim, D. (2012) Trends of Military Unmanned Underwater Vehicle (UUV). Defense and Technology, No. 396, 52-69.

[2] Suh, J., Kim, D. and Lee, H. (2011) Development Trend of Autonomous Unmanned Underwater Vehicle Navigation Technology. Journal of Control, Robotics and Systems, 17, 36-46.

[3] Suh, J. and Choi, J. (2011) Autonomous Skill Level and Development Trend of Autonomous Unmanned Underwater Vehicle. Journal of the Institute of Electronics Engineers of Korea, 38, 20-29.

[4] Choe, J. (2014) Trends in Military Unmanned Surface Vehicle. The Society of Naval Architects of Korea, 51, 3-8.

[5] Yoo, T. and Kim, M. (2014), Analysis of Integrated Navigation Performance for Sensor Selection of Unmanned Underwater Vehicle (UUV). The Korean Society of Ocean Engineers, 28, 566-573.

[6] Farman, A., Kim, E. and Kim, Y. (2015) Type-2 Fuzzy Ontology-Based Semantic Knowledge for Collision Avoidance of Autonomous Underwater Vehicles. Information Sciences, 295, 441-464.

[7] Zhao, Y., Wang, L. and Peng, S. (2016) A Real-Time Collision Avoidance Learning System for Unmanned Surface Vessels. Neurocomputing, 182, 255-266.

[8] Liu, D., et al. (2016) Dynamic Replanning Algorithm of Local Trajectory for Unmanned Surface Vehicle. 35th Chinese Control Conference, Chengdu, 27-29 July 2016, 7120-7125. https://doi.org/10.1109/chicc.2016.7554482

[9] Lee, Y.-I., Jung, H. and Kim, Y.-G. (2007) An Autonomous Navigation System for Unmanned Underwater Vehicle. Korea Information Science Society, 34, 235-245.

[10] Kuwata, Y., et al. (2014) Safe Maritime Autonomous Navigation with Colregs, Using Velocity Obstacles. IEEE Journal of Oceanic Engineering, 39, 110-119. https://doi.org/10.1109/JOE.2013.2254214

[11] Yao, H., et al. (2016) Research on Situation Awareness Based on Ontology for UUV. 2016 IEEE International Conference on Mechatronics and Automation, Harbin, 7-10 August 2016, 2500-2506. https://doi.org/10.1109/icma.2016.7558959

[12] Annamalai, A.S.K., et al. (2015) Robust Adaptive Control of an Uninhabited Surface Vehicle. Journal of Intelligent \& Robotic Systems, 78, 319-338. https://doi.org/10.1007/s10846-014-0057-2

[13] Park, J., et al. (2016) Development of an Unmanned Surface Vehicle System for the 2014 Maritime RobotX Challenge. Journal of Field Robotics. 
https://doi.org/10.1002/rob.21659

[14] Liu, Y. and Bucknall, R. (2015) Path Planning Algorithm for Unmanned Surface Vehicle Formations in a Practical Maritime Environment. Ocean Engineering, 97, 126-144.

[15] Pearson, D., et al. (2014) High-Level Fuzzy Logic Guidance System for an Unmanned Surface Vehicle (USV) Tasked to Perform Autonomous Launch and Recovery (ALR) of an Autonomous Underwater Vehicle (AUV). Autonomous Underwater Vehicles, Oxford, 6-9 October 2014, 1-15.

Submit or recommend next manuscript to SCIRP and we will provide best service for you:

Accepting pre-submission inquiries through Email, Facebook, LinkedIn, Twitter, etc. A wide selection of journals (inclusive of 9 subjects, more than 200 journals)

Providing 24-hour high-quality service

User-friendly online submission system

Fair and swift peer-review system

Efficient typesetting and proofreading procedure

Display of the result of downloads and visits, as well as the number of cited articles Maximum dissemination of your research work

Submit your manuscript at: http://papersubmission.scirp.org/

Or contact jcc@scirp.org 